\title{
Una memoria incómoda. La guerra de Malvinas en los gobiernos kirchneristas (2003-2015) ${ }^{1}$
}

\begin{abstract}
Resumen
En Argentina las memorias de la guerra de Malvinas se han superpuesto y entrado en conflicto desde la derrota frente a los ingleses en junio de 1982. Este artículo busca analizar la gestión de la memoria en torno a la guerra a la que apelaron los gobiernos kirchneristas (2003-2015). Los usos políticos del pasado de este acontecimiento implicaron un desafío, dado que la guerra fue promovida y declarada por un gobierno dictatorial y unas Fuerzas Armadas duramente criticadas por la violación a los derechos humanos. Emergió así, durante el kirchnerismo, una memoria incómoda que buscaba compatibilizar la reivindicación nacionalista de la causa Malvinas con la defensa de los derechos humanos y los cuestionamientos a la dictadura. El objetivo del artículo es mostrar la forma en que varió la memoria oficial de la guerra entre el gobierno de Néstor Kirchner (2003-2007) y el de Cristina Fernández de Kirchner (2007-2015). El corpus documental en el que se detiene este análisis está constituido por todos los discursos presidenciales que mencionaron a la guerra y por el guion museográfico del Museo de Malvinas, inaugurado por el gobierno en junio de 2014.
\end{abstract}

Palabras clave: Argentina, Malvinas, memoria, guerra.

Referencia para citar este artículo: PEROCHENA, Camila (2016). "Una memoria incómoda. La guerra de Malvinas en los gobiernos kirchneristas (2003-2015)". En Anuario de Historia Regional y de las Fronteras. 21 (2). pp. 173-191.

Fecha de recepción: 01/12/2015

Fecha de aceptación: 22/02/2016

Camila Perochena: Doctora en Historia, Universidad Nacional de Buenos Aires (en curso). Magíster en Ciencias Políticas, Universidad Torcuato Di Tella, Buenos Aires. Profesora de Historia, Facultad de Humanidades y Artes de la Universidad Nacional de Rosario. Correo electrónico: camipero@gmail.com.

\footnotetext{
${ }^{1}$ Una versión preliminar de este artículo fue discutida como ponencia en las XV Jornadas Interescuelas/ Departamentos de Historia, Comodoro Rivadavia, septiembre del 2015.
} 


\title{
An Uncomfortable Memory. The Falklands War in Kirchnerist Governments (2003-2015)
}

\begin{abstract}
In Argentina, the memories of the Falklands War have overlapped and conflicted since the defeat against the English in June 1982. This article seeks to analyze the memory management about the war that Kirchnerist governments appealed to (20032015). The political uses of the past of this event involved a challenge since the war was promoted and declared by a dictatorial government and some harshly criticized Armed Forces due to human rights violation. Thus, during Kirchnerist governments, an uncomfortable memory that sought to reconcile the nationalist claim of the Malvinas cause with the defense of human rights and the challenges to the dictatorship. The aim of the paper is to show the way the official memory of the war changed between the government of Nestor Kirchner (2003-2007) and the one of Cristina Fernandez de Kirchner (2007-2015). The documentary corpus in which this analysis lies consists of all presidential speeches mentioning the war and the museum script of the Malvinas Museum, opened by the government in June 2014.
\end{abstract}

Keywords: Argentina, Malvinas, Memory, War.

\section{Uma memória incômoda. A guerra das Malvinas nos governos kirchneristas (2003-2015)}

\section{Resumo}

Na Argentina as memórias da guerra das Malvinas foram sobrepostas e entraram em conflito desde a derrota diante dos ingleses em junho de 1982. Este artigo busca analisar a gestão da memória em torno à guerra à que apelaram os governos kirchneristas (2003-2015). Os usos políticos do passado deste acontecimento implicaram um desafio, dado que a guerra foi promovida e declarada por um governo ditatorial e umas Forças Armadas duramente criticadas pela violação aos direitos humanos. Desta forma, durante o kirchnerismo emergiu uma memória incômoda que buscava compatibilizar a reivindicação nacionalista da causa Malvinas com a defesa dos direitos humanos e os questionamentos à ditadura. O objetivo do artigo é mostrar a forma em que variou a memória oficial da guerra entre o governo de Néstor Kirchner (2003-2007) e o de Cristina Fernández de Kirchner (2007-2015). O corpus documental no qual concentra-se esta análise está constituída por todos os discursos presidenciais que mencionaram a guerra e pelo roteiro museugráfico do Museu das Malvinas, inaugurado pelo governo em junho de 2014.

Palavras chave: Argentina, Malvinas, memória, guerra. 


\section{Introducción}

El 2 de abril de 1982, el gobierno militar que gobernaba a Argentina desembarcó en las islas Malvinas que se encontraban bajo el poder de Gran Bretaña desde 1833. En un contexto de crisis económica y desprestigio político de las Fuerzas Armadas, la recuperación de las Malvinas, una reivindicación histórica de la tradición nacionalista argentina, parecía ser una oportunidad para dispensar legitimidad al régimen. La ocupación, que un mes después derivó en una guerra contra Gran Bretaña, contó con un vasto apoyo de la opinión pública y de dirigentes civiles. No obstante, la guerra finalizó rápidamente -el 14 de junio- con la rendición de Argentina, marcando así el colapso del régimen militar y el inicio de la transición democrática.

La guerra de Malvinas dejó densas capas de memoria individual y social que se superpusieron, complementaron y entraron en conflicto desde 1982. Dichas memorias son muy diferentes a los discursos construidos en torno a las guerras del siglo XIX, cuyo recuerdo permitió forjar la identidad de la nación. Los protagonistas guerreros decimonónicos se incluyeron en el Panteón de Héroes de la Patria y representaron un modelo para formar ciudadanos. Pero la guerra de Malvinas se resiste a los usos tradicionales del pasado y a inscribirse en la genealogía trazada para el siglo XIX. Estas dificultades se deben, básicamente, a que dicha guerra fue promovida y declarada por un gobierno dictatorial y unas Fuerzas Armadas, duramente cuestionadas por la represión interna que ejecutaron en esos años.

Durante las presidencias de Néstor Kirchner (2003-2007) y Cristina Fernández de Kirchner (2007-2015), la cuestión Malvinas cobró una renovada importancia conjuntamente con la reapertura de los juicios perpetrados a los militares que participaron de la dictadura militar entre 1976 y 1983. La recuperación del tema de la guerra por parte de los gobiernos kirchneristas estuvo atravesada por su vocación refundacional del sistema político, por las tensiones que heredaron de las memorias precedentes y por las propias variaciones que presentaron las coyunturas en las que se desplegó el discurso memorialista. Las dificultades para compatibilizar la reivindicación nacionalista de la causa Malvinas con la defensa de los derechos humanos y los cuestionamientos a la dictadura, dieron por resultado una memoria incómoda. A la exploración de esos nichos de incomodidad está destinado el presente artículo en el que se recorren las imágenes exhibidas sobre la guerra de Malvinas en los discursos emitidos desde el Poder Ejecutivo entre 2003 y 2015.

El tema se inscribe en los estudios sobre memoria, y dentro de este vasto objeto se apela a la noción de usos políticos del pasado como instrumento ideológico y de poder que permite consolidar la legitimidad política. Según esta perspectiva, las sociedades y los gobiernos se apropian del pasado, lo conmemoran y lo recrean en función del presente $^{2}$. En el caso que ocupa, el interés por crear una memoria oficial en torno a

\footnotetext{
${ }^{2}$ Sobre los usos políticos del pasado: Hobsbawm, Eric y Ranger, Terence. The invention of tradition (Cambridge/New York: Cambridge University Press, 1982); Nora, Pierre (Dir.). Les lieux de memoire (París: Gallimard, 1997); Kammen, Michael. Mystic chords of memory (New York: Vintage Books, 1993).
} 
la guerra de Malvinas -se entiende a la memoria oficial como el intento de definir y reforzar sentimientos de pertenencia que apuntan a mantener la cohesión social y a defender fronteras simbólicas ${ }^{3}$ - se enfrentó a las memorias que lo precedieron y a las propias tensiones emanadas de los actores involucrados en ellas. Esa memoria oficial -que como toda memoria producida desde un gobierno nunca es unívoca, triunfante e incontestada ${ }^{4}$ - debió gestionar tales tensiones, revelándose las dificultades que la tarea implicaba. ¿Qué lugar debían ocupar las Fuerzas Armadas y los derechos humanos en esa memoria? ¿Cómo malvinizar el discurso político y, simultáneamente, cuestionar la dictadura mediante la reivindicación de la verdad y la justicia? La historia se constituyó así en un campo de disputa dentro de la arena política por cuanto el discurso oficial debió recoger, seleccionar y articular las diversas memorias que fueron cimentándose sobre el hecho conmemorado.

En esta dirección, la primera parte del artículo - de carácter introductorio- está destinada a describir las memorias construidas en torno a Malvinas desde la transición democrática hasta la llegada del kirchnerismo al poder en el 2003. Sobre la base de la bibliografía más destacada que ha abordado el tema, se presenta allí el mosaico de las memorias evocadas por soldados, familiares, Fuerzas Armadas y partidos en el poder. En los dos apartados siguientes se desarrolla el tema central, donde el foco de atención está puesto en la gestión de la memoria oficial tramitada y disputada entre 2003 y 2015 para definir los recuerdos y olvidos en torno a Malvinas. Dichos apartados corresponden respectivamente con las presidencias de Néstor Kirchner (en adelante NK) y Cristina Fernández de Kirchner (en adelante CFK). Además de considerar las principales políticas públicas que, vinculadas al tema, se desarrollaron en sendos gobiernos, el corpus documental en el que se detiene este análisis está constituido por todos los discursos emitidos desde el Poder Ejecutivo en torno a la guerra y se cierra con el guión museográfico del Museo de Malvinas inaugurado por el gobierno de CFK en junio de 2014. Se busca mostrar en las siguientes páginas cómo el intento posterior a 2003 de crear una memoria oficial sobre la guerra contra Gran Bretaña, reveló variaciones tanto entre las dos presidencias del matrimonio Kirchner como dentro mismo de cada uno de sus gobiernos.

\section{Las memorias de la guerra}

Las diferentes imágenes y discursos que circularon en torno a la guerra de Malvinas luego de 1982 fueron abordados por diversos autores, entre los que se destacan Federico Lorenz, Rosana Guber y Vicente Palermo. A partir de sus investigaciones se pueden distinguir tres relatos que se contrapusieron luego de la derrota, donde la guerra adquirió diversos significados.

El primero fue el que comenzó a circular en la opinión pública en los primeros meses de la posguerra. Este relato consideraba a la guerra como una aventura comandada

\footnotetext{
3 Pollak, Michael. Memoria, olvido, silencio (La Plata: Editorial al Margen, 2006).

${ }^{4}$ Cattaruzza, Alejandro. "Dimensiones políticas y cuestiones historiográficas en las investigaciones históricas sobre la memoria", en Storiografia. Rivista Annuale di Storia, núm. 16, Roma, año 2012, pp. 71-91.
} 
por jefes militares irresponsables que llevaron a jóvenes sin experiencia a enfrentarse a una muerte segura. De esta forma, la reivindicación territorial y la guerra se unían a los objetivos del régimen militar, degradándola al rango de guerra absurda ${ }^{5}$. Tal como lo explica Vicente Palermo, este relato buscó separar tajantemente la causa Malvinas de la propia guerra, atribuyéndole a los militares la decisión de ocupar las islas ${ }^{6}$. Aquí se presentaba a los soldados conscriptos (aquellos que fueron reclutados por estar cumpliendo el servicio militar obligatorio vigente en aquel momento) como víctimas del maltrato de los oficiales y de un gobierno de facto que los envió a la guerra en condiciones inhumanas y sin preparación. En esta visión, el lugar del enemigo no estaba ocupado por los británicos sino por los generales y almirantes genocidas. Según Lorenz ${ }^{7}$, esta perspectiva victimizaba a los soldados a quienes les quitaba su capacidad de agencia, nombrándolos bajo la etiqueta de chicos de la guerra. Al mismo tiempo, anulaba el apoyo que la sociedad le dio a la guerra al presentarla como víctima del engaño, el apoyo y la coerción ${ }^{8}$.

El segundo relato fue el patriótico, empleado por las Fuerzas Armadas en 1982 y que hacía hincapié en la identidad nacional y en la guerra como una gesta que debía unir a los argentinos ${ }^{9}$. La guerra era presentada como un enfrentamiento entre naciones encarnadas por sus respectivos estados y ejércitos regulares. Así como los héroes de las guerras de independencia eran tomados como modelo de sacrificio para los ciudadanos, los héroes de Malvinas (y no los chicos de la guerra) debían ser incluidos en el panteón patriótico, sin diferenciar conscriptos y miembros de las Fuerzas Armadas. Dichas fuerzas esgrimieron este relato para defenderse de las acusaciones por la represión ilegal y para presentarse como protagonistas del sacrificio realizado por la nación. Esta perspectiva reproducía una visión esencialista de la guerra y Malvinas se elevaba a una causa sagrada e incuestionable; cualquier duda o crítica que se hiciera sobre ella era tildada de desmalvinizadora ${ }^{10}$.

El tercer relato estuvo representado por la voz de los ex combatientes. Dicha voz se contraponía al primer relato por cuanto no se veían a sí mismos como víctimas sino como agentes históricos que cumplieron con su deber de defender a la patria. Sus visiones, remarca Lorenz, no eran antibélicas ya que la guerra era una experiencia positiva que los aglutinaba y les daba una identidad. Sin embargo, esto no los hacía identificarse con el relato de las Fuerzas Armadas. Los ex combatientes se presentaban como una excepcionalidad dentro de la tradición de exterminio de las Fuerzas Armadas:

\footnotetext{
${ }^{5}$ Guber, Rosana. De chicos a veteranos. Memorias argentinas de la guerra de Malvinas (Buenos Aires: Editorial Antropofagia, 2004), p. 21.

${ }^{6}$ Palermo, Vicente. Sal en las heridas. Las Malvinas en la cultura argentina contemporánea (Buenos Aires: Editorial Sudamericana, 2007), p. 283.

${ }^{7}$ Lorenz, Federico. Las guerras por Malvinas (Buenos Aires: Edhasa, 2012).

${ }^{8}$ Guber, Rosana, Op. cit.

${ }^{9}$ Lorenz, Federico, Op. cit.

${ }^{10}$ Ibid.
} 
[...] reivindicaban una tradición militar vinculada con posturas que se nutrían en el revisionismo histórico y que les permitía construirse como continuadores de una genealogía iniciada por San Martín y su glorioso ejército libertador, el general Güemes, el almirante Brown, los héroes de la Vuelta de Obligado y todos aquellos que honraron su uniforme, contribuyendo al engrandecimiento de la patria ${ }^{11}$.

Cabe aclarar que el revisionismo histórico mencionado en la cita remite en Argentina a un conjunto de interpretaciones históricas nacidas en la década de 1930 por fuera de los ámbitos académicos y cuya característica principal residió en la crítica a una historiografía denominada genéricamente liberal. En esa línea se reivindicó el nacionalismo, un antimperialismo básicamente antibritánico, los caudillos federales del interior y la figura de Juan Manuel de Rosas ${ }^{12}$. El revisionismo fue incorporado más tarde a la tradición peronista y tuvo mucho éxito en instalarse como una suerte de memoria histórica muy difundida hasta la actualidad ${ }^{13}$.

Así, en el discurso de los ex combatientes se denunciaban, por un lado, las asociaciones de Malvinas con la dictadura como operaciones desmalvinizadoras, y por el otro, se postulaba a las Fuerzas Armadas como un ejército popular. Este tercer relato, sin embargo, no fue homogéneo; las divisiones dentro del movimiento de ex soldados "dan cuenta de sus perspectivas sobre la guerra, la nación y el pasado argentino ${ }^{14}$.

Los gobiernos democráticos posteriores a la guerra se enfrentaron, pues, a estas capas de memorias sobre Malvinas. El gran desafío para el gobierno de la transición del presidente Raúl Alfonsín (1983-1989), perteneciente a la Unión Cívica Radical, era cómo conmemorar una derrota que había permitido el restablecimiento de la democracia. Frente a este dilema, Alfonsín esgrimió un discurso democrático basado en el respeto de los derechos humanos, una pieza clave de su gobierno que encaró los juicios a las Fuerzas Armadas por los crímenes perpetrados durante la última dictadura. Según Palermo, Alfonsín se limitó a usar la cuestión de Malvinas "para ajustar las cuentas del modo más seguro con el pasado militar"15. En tal sentido, su primer gesto fue suprimir el feriado del 2 de abril, impuesto por los militares salientes, y trasladarlo al 10 de junio, conmemorando la asunción de Luis Vernet como Comandante Militar de las islas en 1829, representando a las provincias del Río de la Plata. En un discurso emblemático, Alfonsín buscó restituirle a los muertos su civilidad como una forma

\footnotetext{
${ }^{11}$ Ibid., p. 228.

${ }^{12}$ Devoto, Fernando y Pagano, Nora. Historia de la historiografia argentina (Buenos Aires: Sudamericana, 2009), p. 201.

${ }^{13}$ Sobre la tradición revisionista: Halperín Donghi, Tulio. "El revisionismo histórico argentino como visión decadentista del pasado nacional", en Punto de Vista, año VII, núm. 23, Buenos Aires, 1987, pp. 9-17; Cattaruzza, Alejandro. "El revisionismo itinerario de cuatro décadas", en Cattaruzza, Alejandro y Eujanián, Alejandro, Politicas de la historia argentina 1860-1960 (Buenos Aires: Alianza, 2003), pp. 143-185; Quatrocci Woison, Diana. Los males de la memoria. Historia y politica en la Argentina (Buenos Aires: Emecé, 1995), Goebel, Michael. La Argentina partida. Nacionalismos y política de la historia (Buenos Aires: Prometeo Libros, 2013).

${ }^{14}$ Guber, Rosana, Op. cit., p. 28.

${ }^{15}$ Palermo, Vicente, Op. cit., p. 287.
} 
de continuar con la construcción de un panteón republicano, reemplazó la noción de gloria por la de sacrificio y presentó a los combatientes como ciudadanos de uniforme y no como soldados ${ }^{16}$. El entonces presidente se apoyó así en el primero de los relatos difundido entre la opinión pública al separar a los soldados conscriptos de las Fuerzas Armadas y al intentar apropiarse de las consignas nacionalistas en clave republicana.

Esta situación cambió con los levantamientos militares que se produjeron en la Semana Santa de 1987. El objetivo de los militares insurrectos, a quienes llamó carapintadas, era detener los procesos judiciales a los represores de la dictadura militar iniciados durante el gobierno de Alfonsín. Los discursos de los carapintadas hacían numerosas alusiones a Malvinas y al rol que ellos habían cumplido en la guerra. En ese contexto, Alfonsín malvinizó su discurso y se refirió a ellos como héroes de la guerra de Malvinas, dando lugar a una remilitarización de la memoria de la guerra ${ }^{17}$.

Con los gobiernos peronistas de Carlos Menem (1989-1999), la visión en torno a Malvinas mutó radicalmente. Tal como lo ha señalado Lorenz, el nuevo presidente recurrió al discurso en clave patriótica esgrimido por las Fuerzas Armadas, en consonancia con las políticas de olvido del pasado e indultos a los militares decretados durante su gestión. Al mismo tiempo, se utilizó la causa Malvinas para disciplinar y poner bajo la égida del Estado a amplios sectores de ex combatientes. Para ello se formó la Federación de Veteranos de Guerra de la República Argentina que representaba a un sector de los ex combatientes, tanto conscriptos como cuadros de las Fuerzas Armadas, y que guardaba fuertes vínculos con militares carapintadas. Si bien Menem llevó adelante medidas de apoyo a los ex combatientes, fue la Federación el único intermediario institucionalizado entre aquéllos y el gobierno. Con la misma estrategia se creó la Comisión de Familiares de Caídos en Malvinas que tenía muchos miembros en común con la Federación.

Durante el gobierno de la Alianza presidido por Fernando de la Rúa de la Unión Cívica Radical (1999-2001), se restableció como feriado el 2 de abril, una medida que adquiría un profundo significado al restituir el feriado establecido por la dictadura y que la prensa calificó como una concesión a los integrantes de las Fuerzas Armadas. Ya no se conmemoraría el día de la derrota en la guerra, que representaba el inicio de la transición democrática, sino el día del desembarco en las islas ${ }^{18}$.

En este intrincado laberinto de memorias confrontadas en torno a la guerra, los gobiernos kirchneristas reinstalaron el tema de la causa Malvinas en la arena pública. Diversas políticas llevaron adelante durante sus gestiones entre las que se destacan reiterados reclamos ante el Comité de Descolonización de las Naciones Unidas, suspensión de los vuelos hacia Malvinas, pensiones para los veteranos de guerra, creación de la Secretaría de Asuntos Relativos a Malvinas, apertura del Museo Malvinas y desclasificación del Informe Rattenbach (documento emitido por la

\footnotetext{
${ }^{16}$ Lorenz, Federico, Op. cit.

${ }^{17} \mathrm{Ibid}$.

${ }^{18}$ Ibid.
} 
comisión creada bajo el gobierno de Reynaldo Bignone, último presidente de facto, en el que se evaluaba el desempeño de las Fuerzas Armadas durante la guerra de Malvinas). A su vez, la estrategia de regionalizar el conflicto con el apoyo de los países sudamericanos resultó ser una de las políticas más efectivas tomadas al respecto ${ }^{19}$. Todas estas políticas estuvieron acompañadas por discursos oficiales que, como se anunció, variaron en las diversas coyunturas y expresaron distintas combinaciones de las memorias heredadas en consonancia con la identidad política que el kirchnerismo quiso instalar.

\section{Entre el ser nacional y los derechos humanos. La cuestión Malvinas durante la presidencia de Néstor Kirchner (2003-2007)}

Tal como sostiene en un sugerente artículo Aníbal Perez Liñán ${ }^{20}$, NK puede ser definido como un líder de reconstrucción. Se trata de presidentes que se presentan a sí mismos como reconstructores de un régimen democrático, para lo cual "[...] se sitúan en el discurso público de manera distintiva, articulando una narrativa de oposición en referencia al pasado reciente, a los compromisos ideológicos y a la constelación de intereses"21. Lo mismo afirma Javier Zelaznik al explicar que frente a la crisis política, económica y social que experimentó la Argentina y que culminó explosivamente en 2001, el kirchnerismo significó una respuesta política que se articuló con una retórica fundacional. Esta retórica planteó el surgimiento de una Argentina nueva, sin complicidades con el pasado, tanto en las políticas que llevó adelante como en las coaliciones sociales y electorales en las que se basó ${ }^{22}$.

Al tener en cuenta este aspecto, los discursos de NK en torno a la historia nacional buscaron generar una ruptura con los de sus predecesores, en especial los referidos a la historia reciente. Desde su inicio, el presidente impulsó leyes y políticas públicas que pusieron en superficie el debate sobre los derechos humanos y la última dictadura. Entre esas políticas públicas se destacaron la creación del Museo de la Memoria en el predio de la ex ESMA (la Escuela de Mecánica de la Armada donde funcionó un centro clandestino de detención durante la dictadura), la declaración de nulidad e inconstitucionalidad de las leyes de Obediencia Debida y Punto Final sancionadas durante el gobierno de Alfonsín, y la apertura de los juicios a los militares acusados de crímenes de lesa humanidad. Estas políticas hicieron que la historia reciente se convirtiera en protagonista de los debates sostenidos en la arena pública.

Con respecto a los usos políticos del pasado desplegados entre 2003 y 2007, Ana Soledad Montero sostiene que "[...] uno de los rasgos más distintivos y novedosos

\footnotetext{
${ }^{19}$ Battaglino, Jorge. "Una estrategia política eficaz la regionalización del conflicto", Tiempo Argentino, 20 de enero de 2012.

${ }^{20}$ Pérez Liñán, Aníbal. "Liderazgo presidencial y ciclos de poder en la Argentina democrática”, en Revista SAAP, vol. VII, núm. 2, noviembre de 2013.

${ }^{21}$ Pérez Liñán, Anibal, Op. cit., p. 390.

${ }^{22}$ Zelaznik, Javier. "Las coaliciones kirchneristas", en Malamud, Andrés y Luca, Miguel de (coords.), La política en tiempos de los Kirchner (Buenos Aires: Eudeba, 2011), pp. 95-104.
} 
del discurso kirchnerista consiste en haber recuperado un imaginario político nunca antes reivindicado desde la posición de enunciación presidencial: se trata de la 'memoria militante setentista"'23, haciendo referencia con esta expresión al espíritu de época que invadió a los jóvenes militantes de los años setenta, que desde diferentes versiones de la izquierda y de posiciones revolucionarias, imaginaron y representaron la política. Según Montero, NK construyó un ethos que se filió en la generación de jóvenes militantes de los setenta para instaurar sobre ese pilar un nuevo relato acerca del pasado y su propia imagen como líder político. La autora distingue así dos relatos sobre el pasado reciente: un pasado denostado y otro rememorado. El primero abarca los periodos de la dictadura militar y la década menemista -homologándose amboshasta llegar a la crisis del 2001. A pesar de que el kirchenrismo y el menemismo nacen y permanecen dentro del partido peronista, el primero buscó tomar distancia del segundo por sus políticas neoliberales y por el manto de olvido que impuso sobre la dictadura. El pasado rememorado, más intimista, testimonial y subjetivo, se vincula con la militancia setentista y está directamente relacionado con la propia experiencia del locutor.

En esa reinterpretación del pasado reciente, que asumió la defensa de la memoria, la verdad y la justicia como política de Estado y que a la vez reivindicaba los intereses nacionales como una causa prioritaria de gobierno, reflotaba la causa Malvinas. Uno de los primeros gestos políticos de NK hacia el tema tuvo lugar en julio de 2003, durante un encuentro informal con el primer ministro británico Tony Blair, en el que el presidente argentino habló de la soberanía sobre Malvinas como un tema ineludible de $\operatorname{tratar}^{24}$. Por primera vez, luego de la derrota, se volvía a presentar Malvinas como un reclamo histórico centrado en la cuestión de la soberanía. Este énfasis puesto en la soberanía nacional está en consonancia con el discurso que NK dio el 2 de abril de 2004. En algunos fragmentos es posible reconocer claramente tópicos del relato que presentaba a la guerra como una gesta patriótica y a la causa de Malvinas como sagrada e incuestionable:

Hermanos y hermanas, combatientes de Tierra del Fuego presentes aquí: la lucha del 2 de abril no significó, como algunos quieren decir, la decisión loca, atolondrada o suicida de algún general de la Nación, más allá de lo que podría significar. Bajo ningún aspecto se puede emparentar la lucha de los combatientes de Malvinas, de los oficiales dignos de nuestras tres Fuerzas Armadas que combatieron en Malvinas, con aquellos que miraron con la nuca al pueblo argentino y cometieron atropellos [...] Por eso en primer lugar quería estar como presidente de la Nación aquí el 2 de abril para definir y asumir con claridad la adhesión a la conducta, a la defensa de la Soberanía Nacional, a la dignidad, a la calidad de héroes y mártires nacionales que deben ser honrados sin excusas en todo el ámbito de nuestra Patria. (Aplausos) No se puede confundir lo que significó esa lucha con la coyuntura o con las cuestiones mundanas de la política cotidiana ${ }^{25}$.

\footnotetext{
${ }^{23}$ Montero, Ana Soledad. Y al final un día volvimos! Los usos de la memoria en el discurso kirchnerista (2003-2007) (Buenos Aires: Prometeo Libros, 2012), p. 17.

${ }^{24}$ Cibeira, Fernando. "La soberanía es un tema ineludible”, Página 12, 14 de julio del 2003.

${ }^{25}$ NK, conmemoración del XXII aniversario de la gesta de Malvinas, Río Grande, 2 de abril del 2004.
} 
En la misma clave exhibida por los discursos nacionalistas de la guerra, el entonces presidente sostuvo que por encima de cualquier cuestionamiento se encontraba la soberanía nacional y que los sujetos participantes eran los héroes de Malvinas y no los chicos de la guerra. A dichos sujetos se los sustraía del campo de las víctimas de la dictadura o de sus superiores en el que los había colocado el primer relato de posguerra. Los héroes, sostenía NK, deben ser honrados sin excusas, deslizándose la necesidad de homenajear no sólo a los conscriptos sino a todos los miembros de las Fuerzas Armadas que participaron de la guerra. En este primer discurso, entonces, la adscripción sin matices al relato patriótico se contraponía -o al menos entraba en seria tensión- con la política de derechos humanos llevada adelante por el presidente.

En un discurso del 5 de octubre de 2004, NK acentuó esta perspectiva nacionalista en torno a la guerra:

Los veteranos de Malvinas, como les dicen; los chicos, como les quisieron decir algunos tratando de disminuir el valor, la lucha y la conciencia nacional que tuvieron allá en 1982 y que yo los vi llegar al sur para ir a dar la batalla por la Patria; el olvido permanente al que fueron sometidos y al que fue sometida la causa de Malvinas con aquella famosa teoría que decía que había que desmalvinizar el corazón de la Patria, cuando si se hubiera tenido identidad nacional y la calidad de saber lo que es el ser nacional se hubiera tomado con toda fuerza el sentido de la Guerra de Malvinas y de quienes fueron allí a luchar, que no fueron a una guerra por una guerra, no fueron a servir a un gobierno nacional determinado, sino que fueron a servir a esa causa tan noble que es la causa de la soberanía nacional de la Patria, de la dignidad nacional, por la que los argentinos estamos eternamente reconocidos ${ }^{26}$.

La distinción, en este caso, entre veteranos de Malvinas y los chicos de Malvinas remite, además, a la importancia política que señala Federico Lorenz cuando se diferencia entre el concepto de ex combatiente y veterano; una diferencia que no siempre hicieron las bases y que limita la categoría de ex combatientes a los soldados conscriptos y que engloba en la de veteranos tanto a los conscriptos como a los miembros de las Fuerzas Armadas ${ }^{27}$. Por otro lado, el uso del término desmalvinizar no podía sino emparentarse una vez más con el relato nacionalista a la vez que tomaba distancia del gobierno de Alfonsín, acusado por dicho relato de encarnar una política desmalvinizadora. En suma, NK realzaba hasta allí el valor supremo del ser nacional y de la soberanía nacional de la patria.

Esta visión, sin embargo, comenzó a virar en los discursos del año 2006, cuando el presidente se refirió a la guerra como un crimen dictatorial:

Malvinas fue, en un sentido, otro de los crímenes dictatoriales y una gran frustración; la decisión irresponsable de emprender una guerra puso de manifiesto las muchas limitaciones que los técnicos del horror tenían para las verdaderas batallas. Pero Malvinas también es, en otro sentido, un altar de la

\footnotetext{
${ }^{26} \mathrm{NK}$, acto de anuncios a los veteranos de guerra de Malvinas, 5 de octubre del 2004

${ }^{27}$ Lorenz, Federico, Op. cit.
} 
Patria al heroísmo de su pueblo que, como en los orígenes de nuestra corta historia, supo forjar hombres capaces como nuestros Veteranos de Guerra de dar la vida por los demás, de inmolarse por la Patria, aún ante el error estratégico y político de quienes la conducían ilegítimamente en ese momento ${ }^{28}$.

El viraje discursivo coincidía con el clima memorialista que se desplegó en el 2006 por la conmemoración de los 30 años del inicio de la dictadura. Aquí la guerra ya no era solamente una gesta heroica sino también una decisión irresponsable, tomada por un gobierno ilegítimo. En este punto, la toma de distancia respecto de la dictadura no era ajena al modo en que se fue acentuando la política de derechos humanos como un pilar fundamental para legitimar el gobierno de NK. La tensión que sus primeras alocuciones podían generar con dicha política y con una opinión pública muy permeada por la diatriba contra los militares desplazó la enunciación hacia una semántica que sólo continuó criticando a los propulsores de la desmalvinización y realzando la soberanía nacional y el carácter heroico de los soldados:

Por eso, que se hayan cometido las cosas que hemos dicho y demás, jamás podrán invalidar el justo reclamo y es justo decir que las Malvinas son nuestras y argentinas y que estos hermanos que lucharon allá fueron por esos valores, fueron a poner la cara por todos los argentinos, fueron a luchar en desigualdad pero no lloraron, tuvieron la bandera levantada de pie con honor y orgullo ${ }^{29}$.

Aquellos soldados que lucharon en desigualdad pero no lloraron quedaban fuera, una vez más, de la dimensión victimizadora destacada en otros discursos. La no distinción, por otro lado, de conscriptos y cuadros de las Fuerzas Armadas en el lugar de héroes para el Estado se reforzó en algunas ceremonias públicas, como el desfile del ejército realizado el 10 de junio de 2007 por la celebración del Día de la Reafirmación de los derechos argentinos sobre las islas del Atlántico Sur. Ese día marcharon 3000 veteranos, ex conscriptos junto a oficiales y suboficiales,y el jefe del ejército, Roberto Bendini, remarcó que "[...] la gesta de Malvinas hizo resurgir la conciencia nacional de todos los argentinos" 30 y que en 1982 "había llegado el momento de hacer justicia" ${ }^{\prime 1}$.

Las tensiones entre las diversas miradas en torno a la guerra se pusieron en evidencia en la muestra organizada por los 25 años de la guerra, en el año 2007, en la sede del Ministerio de Defensa adonde fueron convocadaslas organizaciones de ex combatientes, las Fuerzas Armadas y diversos $\operatorname{artistas}^{32}$. La titular de dicha cartera ministerial, Nilda Garré, invitó a exponer las distintas visiones existentes en torno a Malvinas. El objetivo de la muestra era lograr una autocrítica de parte de las Fuerzas Armadas sobre los estaqueamientos a los que fueron sometidos algunos soldados

\footnotetext{
${ }^{28} \mathrm{NK}$, conmemoración del día del "veterano de guerra y de los caídos en las guerra de Malvinas", 2 de abril del 2006.

${ }^{29}$ Ibid.

30 "Bendini reivindicó la Guerra de Malvinas", Perfil, 10 de junio del 2007.

${ }^{31}$ Ibid.

${ }^{32}$ Lorenz, Federico, Op. cit.
} 
durante la guerra. En ese contexto, la Comisión de Familiares de Caídos se retiró del evento porque el CECIM La Plata-organización de ex combatientes que solo admite ex soldados conscriptos y que impulsa los juicios por delitos de lesa humanidad cometidos por oficiales y suboficiales hacia miembros de su propia tropa- instaló el maniquí de un soldado estaqueado que denunciaba los abusos sufridos por los combatientes por parte de sus superiores. El CECIM buscaba que aquellos oficiales se hicieran cargo "de los errores que cometieron, porque no podemos poner en el panteón nacional a torturadores como héroes" ${ }^{33}$ por cuanto se trataba de "un capítulo que no está saldado y no ha concluido"34, según sostuvo Ernesto Alonso, integrante de dicha asociación. La muestra de 2007 dotó de mayor visibilidad al primero de los relatos en torno a Malvinas aquí descriptos y puso en evidencia las críticas que despertaba entre muchos el discurso épico expresado hasta ese momento por el Poder Ejecutivo.

\section{Entre los derechos humanos y la larga genealogía de una guerra. La cuestión Malvinas durante las presidencias de Cristina Fernández de Kirchner (2007-2015)}

Durante los dos gobiernos de CFK se ejecutaron numerosas políticas en relación con la cuestión Malvinas. Entre ellas se destacan la desclasificación del Informe Rattenbach, la creación de la Secretaría de Asuntos Relativos a Malvinas y la creación del Museo de Malvinas. Si la aplicación de políticas específicas marca en algún sentido cierta continuidad con la presidencia de su marido, en los discursos y en el significado otorgado a dichas políticas, se advierten cambios significativos respecto al tema que ocupa.

El primero de ellos fue la clara inscripción de la guerra de Malvinas como una cuestión de memoria, verdad y justicia. CFK retomó así algunas demandas presentes en los reclamos de los organismos de derechos humanos y de algunas organizaciones de ex combatientes como el CECIM La Plata. Un momento simbólico fue, en este sentido, el acto organizado en Ushuaia en 2012 -la ciudad más austral que sirvió de base de operaciones durante la guerra- para conmemorar el $30^{\circ}$ aniversario del conflicto contra Gran Bretaña. En esa oportunidad se trasladaron ex combatientes de todo el país para realizar una vigilia en las plazas donde se proyectaron documentales y realizaron muestras. Luego de la vigilia, en el acto oficial, la presidenta sostuvo:

Esa verdad que revela que no fue una decisión del pueblo argentino la del 2 de abril, que ni siquiera estaba atrás de ella el intento válido de ejercer soberanía y rechazar el colonialismo, sino apenas un intento de lo que muchas veces nos acusan a los políticos que es de perpetuarse en el poder. [...] Memoria y verdad, entonces y, fundamentalmente, que se descorra el telón que pretende hacer creer el Reino Unido, que aquella decisión fue una decisión del pueblo argentino.

\footnotetext{
${ }^{33}$ Minutouno.com. Malvinas... una cosa que duele, http://www.minutouno.com/notas/27556-malvinasuna-cosa-que-duele (16 de mayo del 2007).

${ }^{34}$ Ibid.
} 
Había presos sin nombre ni apellido en campos de concentración; había detenidos desaparecidos que nunca volverán a aparecer. Parece ser que no se dan por enterados. Es que tal vez sea el último justificativo que cada día resulta más absurdo, más ridículo, más inverosímil ante los ojos de un mundo que ve -y lo digo con orgullo- a este país, mi país, la República Argentina, por decisión política del entonces presidente Kirchner y también por la decisión de esta Presidenta, de convertir la política de Derechos Humanos en uno de los pilares de Estado ${ }^{35}$.

Este discurso fue, en primer lugar, una respuesta a los dichos del primer ministro británico David Cameron que, en el homenaje por los 30 años de la guerra realizado en Inglaterra, afirmó que "en 1982 Argentina violó los derechos de los isleños"36. El conflicto bélico era representado por Cameron como un acto de agresión que apuntaba a robar la libertad de los habitantes de la isla ${ }^{37}$, enfatizándose así la postura de autodeterminación que presupone el derecho de los isleños a decidir en torno a la soberanía. En segundo lugar, CFK dejaba en evidencia una torción discursiva significativa respecto del discurso oficial que la precedió al adherir en algunos aspectos al primero de los relatos descriptos al comienzo. La guerra de Malvinas no se tomaba de forma aislada sino que se pensaba a partir de las circunstancias históricas que la generaron -la dictadura militar-, insertándose así en las políticas de memoria, verdad y justicia. En tercer lugar, la idea de desmalvinización adquirió también un significado diferente. Además de evocar el intento de olvidar la guerra y a los combatientes, el término se amplió para referir al gesto de identificar Malvinas con la dictadura

Comenzó allí un proceso de desmalvinización. Algunos, tal vez, con la buena fe de identificar dictadura con Malvinas; otros, tal vez, como una estrategia sutil e inteligente -sutil e inteligente- para, precisamente, lograr el propósito y el objetivo final: que los argentinos renunciáramos definitivamente a lo que nos corresponde ${ }^{38}$.

Los héroes de la guerra eran vistos desde otra perspectiva, incorporados a una juventud que no estaba lista para ir a un conflicto bélico y que los reubicaba en el campo de las víctimas:

¿Por qué será que la historia se lleva siempre a los más jóvenes en los momentos difíciles? Por eso mi reconocimiento a esa juventud que marchó a las Islas, sin preparación, sin los pertrechos suficientes, sin la formación, yo diría muchos también con miedo. ¿Quién no siente miedo de ir a la guerra? Los que no sienten miedo no son los valientes. Valientes son los que avanzan aún con miedo ${ }^{39}$.

\footnotetext{
${ }^{35} \mathrm{CFK}$, Acto por el $30^{\circ}$ aniversario de la guerra de Malvinas, 2 de abril del 2012.

36 "No pedimos otra cosa que diálogo para resolver la soberanía", Página 12, 3 de abril del 2012, http:// www.pagina12.com.ar/diario/elpais/1-191033-2012-04-03.html.

37 "Cameron: «Se buscó robar la libertad de los isleños»", La Nación, 2 de abril del 2012. http://www. lanacion.com.ar/1461634-cameron-se-busco-robar-la-libertad-de-los-islenos.

${ }^{38} \mathrm{CFK}$, acto de homenaje a los caídos en Malvinas a 28 años del comienzo del conflicto bélico, Ushuaia, 2 de abril del 2010.

${ }^{39} \mathrm{CFK}$, Acto por el $30^{\circ}$ aniversario de la guerra de Malvinas, 2 de abril del 2012.
} 
Ahora bien, la marca más original de la posición adoptada por CFK respecto de Malvinas fue la perspectiva histórica de largo plazo en la que la inscribió. La presidenta incorporó la guerra de 1982 en la genealogía de batallas decimonónicas, intentando articular así la tradición nacionalista con los discursos en torno a la memoria, la verdad y la justicia. Esta filiación en la larga duración le permitía diluir o atenuar las contradicciones inherentes a Malvinas en la construcción de ambas memorias. Dicha genealogía ubicaba a Malvinas en un proceso que abarcaba dos siglos de historia y que se podía rastrear desde las invasiones inglesas en 1806 y 1807, pasando por la batalla de la Vuelta de Obligado en 1845, consagrada por la presidenta con un nuevo feriado nacional para recordar el intento del gobierno de Juan Manuel de Rosas de frenar el avance fluvial de las tropas que conformaron el bloqueo anglo-francés al puerto de Buenos Aires:

Creo que el hecho colonial, colonial por historia, porque también creo que deberíamos comenzar a considerar los argentinos los días 2 y 3 de enero, del año que viene, se van a cumplir 180 años exactos de la usurpación y el desalojo de los argentinos de nuestras Islas Malvinas deberíamos comenzar a considerar también esta fecha (APLAUSOS). Fecha que - por cierto- no es la única en los intentos que hubo de someternos, si vamos un poquito más atrás de 1833 , nos vamos a encontrar el 1806 -cuando aún éramos colonia española- y en 1807, rechazando las invasiones inglesas. Y más tarde -bajo la égida del Brigadier General Don Juan Manuel de Rosas, en el año 45, rechazando también el bloqueo anglo-francés. (APLAUSOS) ${ }^{40}$.

La recuperación de la línea histórica trazada por el revisionismo histórico fue muy persistente durante la gestión de la presidenta y no se limitó sólo a la causa Malvinas. En todo caso, Malvinas era un tópico que permitía explotar de manera directa y sin cortapisas su discurso antimperialista a través del contraste entre la reivindicación de la soberanía nacional y el coloniaje. Puesta en esa temporalidad, CFK podía distinguir lo que NK no había diferenciado: la dictadura militar no había iniciado la guerra como una lucha contra el colonialismo, como expresó en el discurso citado de 2012, sino que se había valido de ella para perpetuarse en el poder.

Los rasgos revisionistas del discurso Malvinas se reforzaron con la reivindicación del Gaucho Rivero, personaje que formó parte de un alzamiento en las islas contra los ingleses en 1833. Esta figura, que según sostienen los revisionistas fue invisibilizado por la historia liberal, pasó a formar parte en el 2015 de un nuevo billete de 50 pesos. El 24 de agosto de 2012, CFK realizó un acto de homenaje en su memoria afirmando que quería "[...] recordarlo a él porque lo anonimaron [...], lo desaparecieron, $[\ldots]$ lo difamaron diciendo que era un bandolero" ${ }^{41}$, y concluía diciendo que "el Gaucho Rivero muere, como no podía ser de otra manera, en la Vuelta de Obligado"42.

Como parte de una apuesta mucho más ambiciosa en el plano de los usos políticos de la historia, la presidenta reinterpretó la guerra de 1982 como un episodio más

\footnotetext{
${ }^{40}$ Ibid.

${ }^{41}$ CFK, Acto de homenaje al Gaucho Rivero, 24 de Agosto del 2012.

${ }^{42}$ Ibid.
} 
dentro de la supuesta invisibilización que la llamada historia oficial hizo de todos los acontecimientos que a lo largo de dos siglos expresaron la lucha popular y antimperialista. Dicha apuesta quedó plasmada claramente en el Museo de Malvinas, destinado a visibilizar aquello que CFK venía anunciando en sus discursos. Inaugurado en junio de 2014, el Museo de Malvinas se instaló por decisión presidencial en el simbólico predio que había ocupado la ESMA. Aquel tenebroso lugar de detención y represión clandestina de la dictadura militar, convertido en Espacio Memoria durante la presidencia de NK, alojaba ahora la memoria de Malvinas a la vez que intentaba consagrar una memoria oficial sobre la guerra:

Por eso, también, hemos decidido que esta construcción, que este Museo, tuviera lugar en este sitio de la memoria, en la ex ESMA, por esto que acabo de mencionar, que la historia no se puede fragmentar ni tomar con beneficio de inventario. Y nosotros que tenemos en la memoria uno de los pilares fundamentales de nuestras políticas, hemos querido también hacerlo aquí ${ }^{43}$.

Para la construcción del Museo de Malvinas se demolió en el 2012 un pabellón de dormitorios que pertenecía a la ESMA, una decisión que -como destaca Adrián Gorelik - se caracterizó por la ausencia total de debate en el espacio público en torno a esta política de memoria ${ }^{44}$. El guión museográfico presenta al Museo Malvinas desplegado en cuatro etapas: vida, pasión, muerte y resurrección. La vida se corresponde con la flora y fauna de las islas, la pasión con los numerosos reclamos de soberanía realizados a lo largo de los siglos XIX y XX, la muerte con la guerra de 1982 y, finalmente, la resurrección con la causa Malvinas recuperada durante las presidencias de los Kirchner. El contenido mesiánico de la metáfora que estructura el guion museográfico le otorga al kirchnerismo el lugar de redentor de la causa de la soberanía nacional e inscribe a la guerra de Malvinas en una temporalidad histórica de larga duración, en sintonía con el discurso desarrollado hasta allí por CFK. Esa larga historia inicia en 1520 con el descubrimiento de las islas, y se cierra en el 2014. Como sostuvo el director del Museo, Jorge Giles: "No será el museo de la guerra, sino que recorrerá toda la vida e historia de las islas" ${ }^{\prime 4}$.

La línea histórica contiene, por un lado, menciones a episodios históricos relacionados directamente con las islas y, por otro lado, referencias históricas que no guardan relación directa con la cuestión Malvinas pero que se las busca asociar a ella desde un discurso que defiende la soberanía nacional. Entre las primeras referencias se destacan: el descubrimiento de las islas; las legislaciones del gobierno argentino entre $1820 \mathrm{y}$ 1824 referidas a Malvinas; la asunción de Vernet como comandante-gobernador; la ocupación británica de 1833; el levantamiento del Gaucho Rivero; diversas menciones de escritores sobre la soberanía de las islas; el aterrizaje de Fitzgerald en Malvinas para enarbolar una bandera argentina en 1964; la resolución 2065 de la ONU, aprobada en 1965 en la que se reconoce la existencia de una disputa de soberanía entre el reino

\footnotetext{
${ }^{43}$ CFK, Inauguración del Museo Malvinas en la ex ESMA, 10 de junio del 2014.

${ }^{44}$ Gorelik, Adrián. "Materiales de la memoria", en Informe Escaleno, 29 de marzo del 2014, http://www. informeescaleno.com.ar/index.php?s=articulos\&id=134 (28 de noviembre del 2015).

45 “Un museo para Malvinas", Pagina 12, 7 de junio del 2014.
} 
Unido y Argentina en torno a Malvinas; el Operativo Cóndor de 1966 que implicó una acción armada por parte de argentinos que desviaron un avión civil de Aerolíneas Argentinas para obligarlo a aterrizar en las islas; la guerra contra Gran Bretaña de 1982; el apoyo de la UNASUR a la causa Malvinas; la desclasificación del Informe Rattenbach y la creación del Museo.

Estos acontecimientos se intercalan con otros, cuya selección se nutre de la línea histórica revisionista ya mencionada: las invasiones inglesas; el empréstito que firmó el ministro de gobierno Bernardino Rivadavia en 1822 con la firma británica BaringBrothers, por lo que los revisionistas le atribuyen a dicho ministro ser el inventor de la deuda externa argentina; el combate de la Vuelta de Obligado donde algunos historiadores afirman que murió el Gaucho Rivero; la Guerra de la Triple Alianza en la que la coalición formada por Argentina, Brasil y Uruguay derrotó al Paraguay en 1870 y en la que Inglaterra alentó la destrucción de la fuerte industria paraguaya; el 17 de octubre de 1945 que simboliza el surgimiento de Juan Domingo Perón como líder del movimiento nacional-popular; el triunfo de Perón en las elecciones de 1946 y la nacionalización de los ferrocarriles realizada durante su primer gobierno.

El Museo se convierte así en una reivindicación de la soberanía nacional sobre las islas, pero donde la guerra de 1982 representa un acontecimiento más dentro de un largo continuum que interpreta a dicha guerra como derivación lógica asentada en un fundamento histórico. Dentro de este relato museográfico, el principal enemigo está encarnado por Gran Bretaña, cuya intervención en la historia argentina se puede observar en tres paneles titulados Británicos en la Argentina. En esos paneles se desarrollan las invasiones inglesas, la Vuelta de Obligado, el empréstito Baring Brothers, el pacto comercial Roca-Runciman firmado entre Argentina y el Reino Unido en 1933 (considerado un ejemplo de coloniaje pro-británico), la Forestal (compañía inglesa instalada en Argentina desde el siglo XIX para producir tanino), los ferrocarriles de origen británico. Junto a estos paneles se despliegan las diversas luchas por la soberanía: el Gaucho Rivero, Fitzgerald y el Operativo Cóndor. La dicotomía imperialismo y nación ocupa así el centro de la escena.

Mientras todo lo descripto hasta aquí se expone en la planta baja y el primer piso del Museo, la guerra de Malvinas se desarrolla en el segundo piso con el tópico momento kirchnerista. En uno de los paneles sobre el tema se hace alusión al caso de Pedro Edgardo Giachino, un militar que formó parte de la represión durante la dictadura y que, sin embargo, es considerado como un héroe nacional por encontrar la muerte durante la guerra. Con este gesto se busca recuperar un fragmento de la memoria que reclamaba la diferenciación entre militares represores y conscriptos. La guerra, no obstante, queda cristalizada en un guion donde el principal protagonista no es un actor en particular sino la defensa de la soberanía nacional frente a los ingleses. La cuestión de la memoria y la justicia de la guerra parecen quedar así en un segundo plano, intentando desplazar del centro de atención el hecho de que se trató de un conflicto bélico desatado por una dictadura en nombre de la soberanía nacional. 


\section{Reflexión final}

El kirchnerismo intentó gestionar la memoria oficial de la cuestión Malvinas, lidiando con las densas capas de memorias construidas después de la guerra y buscando reforzar a través de ella la vocación refundacional que lo animaba. En ese intento chocó no solo con las tensiones inherentes a las visiones que circulaban y encarnaban los diversos actores involucrados, sino también con las contradicciones nacidas de un discurso que pretendía compatibilizar en la causa Malvinas la reivindicación de la soberanía nacional con la política de derechos humanos. Las variaciones descriptas aquí entre el discurso de NK y el de CFK, como asimismo las que se exhiben dentro de sus respectivas gestiones, revelan un punto central en común: la soberanía nacional debía ocupar el protagonismo. Pero ¿cómo despegarse de las denostadas Fuerzas Armadas que también articularon su gesta a esa reivindicación?

El gradual desplazamiento del discurso patriótico y nacionalista de NK a otro que procuraba atenuar la contradicción con las políticas de derechos humanos impulsadas por su gobierno no logró conciliar las memorias en conflicto. CFK, en cambio, gestionó dichas memorias inclinándose mucho más por las sostenidas por los organismos de derechos humanos y por los excombatientes. Esta variación puede atribuirse, en parte, a la creciente debilidad de las Fuerzas Armadas y a la domesticación que el gobierno logró sobre ellas en esos años, pero también a la más marcada vocación de CFK de hacer un uso político del pasado acentuado en el clima de las celebraciones bicentenarias que coincidieron con la repentina muerte de NK el 27 de octubre de 2010. Esta recurrencia a la historia de dos siglos para legitimar muchas de sus políticas se apoyó, más que nunca, en el difundido sentido común instalado por el revisionismo histórico y que formaba parte del background del que el matrimonio Kirchner se había nutrido en los años setenta. Ese sentido común, que reforzaba una visión dicotómica del pasado para anclar en un presente también dividido entre defensores y enemigos de un proyecto nacional-popular, contribuyó a reubicar la guerra de Malvinas en un arco temporal que buscaba diluir las tensiones heredadas. Aislarla de las circunstancias históricas que la generaron para inscribirla en un continuum de lucha contra el imperialismo británico parecía una salida capaz de liquidar la incomodidad manifiesta que acompañó la causa Malvinas desde sus inicios.

Sin embargo, esa gestión de memoria que parece concluir con el Museo de Malvinas no está exenta de contradicciones y disputas. El Museo revela la persistencia de esa incomodidad, donde los silencios son reemplazados por elocuentes líneas históricas. Su emplazamiento en la ESMA para inscribir la cuestión Malvinas en un sitio de memoria sigue exhibiendo las tensiones con una parte de esa memoria. Los silencios del Museo, por otro lado, contrastan con las voces de algunos ex soldados que todavía hoy se hacen sentir disruptivamente en el espacio público. Un grupo de ex conscriptos que cumplieron servicio militar en la Patagonia durante el conflicto armado contra Gran Bretaña, reclaman ser reconocidos como veteranos de guerra aunque no hayan combatido en las islas. Sus demandas se expresan actualmente a través de piquetes y 
bloqueos de tránsito en lugares emblemáticos de la capital federal, como la Plaza de Mayo o la intersección de la avenida 9 de Julio con la avenida de Mayo. La gestión de la memoria Malvinas parece no estar aún saldada.

\section{Bibliografía}

\section{Fuentes primarias}

\section{Artículos de prensa}

La Nación, Buenos Aires, 2012.

Minutouno.com, Buenos Aires, 2007.

Página 12, Buenos Aires, 2003.

Página 12, Buenos Aires, 2012.

Página 12, Buenos Aires, 2014.

Perfil, Buenos Aires, 2007.

Tiempo Argentino, Buenos Aires, 2012.

\section{Fuentes secundarias}

\section{Libros}

Goebel, Michael. La Argentina partida. Nacionalismos y politica de la historia. Buenos Aires: Prometeo Libros, 2013.

Guber, Rosana. De chicos a veteranos. Memorias argentinas de la guerra de Malvinas. Buenos Aires: Editorial Antropofagia, 2004

Hobsbawm, Eric y Ranger, Terence. The invention of tradition. Cambridge/New York: Cambridge University Press, 1982.

Kammen, Michael. Mystic chords of memory. New York: Vintage Books, 1993.

Lorenz, Federico. Las guerras por Malvinas, Buenos Aires: Edhasa, 2012.

Montero, Ana Soledad. Y al final un día volvimos! Los usos de la memoria en el discurso kirchnerista (2003-2007). Buenos Aires: Prometeo Libros, 2012.

Nora, Pierre (Dir.). Les lieux de memoire. París: Gallimard, 1997. 
Palermo, Vicente. Sal en las heridas. Las Malvinas en la cultura argentina contemporánea. Buenos Aires: Editorial Sudamericana, 2007.

Pollak, Michael. Memoria, olvido, silencio. La Plata: Editorial Al Margen, 2006.

Quatrocci Woison, Diana. Los males de la memoria. Historia y politica en la Argentina. Buenos Aires: Emecé, 1995.

\section{Capítulos de libros}

Cattaruzza, Alejandro. "El revisionismo itinerario de cuatro décadas", en Cattaruzza, Alejandro y Eujanián, Alejandro, Políticas de la historia argentina 1860-1960. Buenos Aires: Alianza, 2003.

Zelaznik, Javier. "Las coaliciones kirchneristas”, en Malamud, Andrés y Luca, Miguel de (coords.), La política en tiempos de los Kirchner. Buenos Aires: Eudeba, 2011.

\section{Artículos en revistas}

Cattaruzza, Alejandro. "Dimensiones políticas y cuestiones historiográficas en las investigaciones históricas sobre la memoria", en Storiografia. Rivista Annuale di Storia, núm.16, 2012.

Halperín Donghi, Tulio. "El revisionismo histórico argentino como visión decadentista del pasado nacional”, en Punto de Vista, año VII, núm. 23, Buenos Aires, 1987.

Pérez Liñán, Aníbal. "Liderazgo presidencial y ciclos de poder en la Argentina democrática", en Revista SAAP, vol. VII, núm. 2, 2013.

\section{Publicaciones en Internet}

Discursos presidenciales, http://www.casarosada.gob.ar/informacion/discursos.

Gorelik, Adrián. "Materiales de la memoria”, en Informe Escaleno, 29 de marzo del 2014, http://www.informeescaleno.com.ar/index.php?s=articulos\&id=134. 